\title{
TENDENCIES AND SEASONALITY IN THE CHANGE OF THE PRICES OF RESIDENTIAL REAL ESTATES BY NEIGHBORHOODS IN THE CAPITAL OF BULGARIA, SOFIA
}

\author{
Nikolay STOENCHEV ${ }^{\mathbf{1}}$, Yana HRISCHEVA ${ }^{2}$ \\ ${ }^{1}$ University of Forestry, Sofia, Bulgaria \\ ${ }^{2}$ University of National and World Economy, Sofia, Bulgaria \\ Corresponding author's e-mail: hrischeva.y@abv.bg
}

\begin{abstract}
The aim of the present article is to research the availability of rules in the change of the prices of the most spread flats in the neighbourhoods of Sofia. The results from a research in the change of the offered prices of the residential real estates by months for an annual period of time (from October 2016 to September 2017) have been presented. The presence of an uprising tendency for the bigger share of the neighbourhoods has been proven. For those of them where there is a tendency missing are calculated indices for seasonality by the method of the mean chronological value. Upcoming seasonal deviations of the mean monthly prices from the average annual by the separate types of flats (studios, one-bedroom and two-bedroom flats), whereas the highest values are registered in the summer and the early autumn - the months August and September, and the lowest in the late autumn - the months October and November. The most significant are the fluctuations in the variation of the prices in the studios, followed by the two-bedroom flats and one-bedroom flats. The results could be useful to some potential investors.
\end{abstract}

Keywords: Price, residential real estate, seasonality, trends.

\section{INTRODUCTION}

It is logical to expect that in the market prices of the deals with real estates could be a tendency or seasonality. The development of the technologies and the evolution of the needs create conditions for the input of new and more quality materials and the creation of systems for the households, which guarantee better convenience, which leads to an irrevocable rise of the prices. In the same direction leads the availability of inflation however smaller it is. Construction is an economic activity which in geographical areas with clearly defined warm and cold seasons still cannot be done with the same intensity and quality annually. The product of this activity in general is not transportable, although around the world exist convertible houses, which according to area and facility are not much different from the solidly attached to the ground. Although at the market of real estate in Sofia most often flats which are not new construction are present, their repair and put into exploitation also require finishing and refreshing activities, which are not influenced by the air temperatures. Apart from the carrying out of flat inspections by the clients, the buying and transport of the furniture are also easier and more 
pleasant in the warm months. In the availability of all these arguments the question arises if there is not seasonality in the inner annual change of the prices of flats, and how strong it is, are their factors from social or other character which provoke its change and influence its force and could its price be of use to anyone?

The aim of the present article is to research the availability of rules in the change of the prices of the flats in neighbourhoods at the city of Sofia and to discuss the possibility for the extraction of an additional profit by the investors as a result of the better information concerning the nature of the passing processes.

\section{CONDITION OF THE PROBLEM IN THE SCIENTIFIC LITERATURE}

For the research of the tendency and the seasonality are necessary enough monthly data in quality for inhabited points with developed markets of residential real estates. The need of mass accumulations comes from the necessity to eliminate the occasional fluctuations which carry in themselves the single sales or the sale offers. There are not a few researches for such developed markets in advanced or developing industrial states, where there is an intensive process of urbanization or mobility of the population in a territorial aspect due to different reasons. Concerning such research at the territory of seven big cities in Australia announce (Abbas Valadkhani, Andrew C. Worchington \& Russell Smyth, 2015). They use a massive of monthly data for the period of 20 years (1995-2015) for the cities Adelaide, Brisbane, Canberra, Darwin, Hobart, Melbourne, Perth and Sydney, which include the national and regional capitals of the country. Self-regressional models have been worked out through which the change of the flat prices has been represented. The conclusion is made that there are seasonal effects in the change of the prices both in the smallest towns Darwin and Hobart, as well as the biggest Melbourne and Sydney. It is announced a change in the seasonality before and after the financial crisis in 2008. The size of these seasonal deviations in the prices in buying a house after 2008 varies from $+4.6 \%$ at Darwin in March to $3.28 \%$ in June. A clearly defined seasonality has been found out in comparison with those of the separate apartments, located in residential buildings. A wide array of factors is discussed, influencing on the seasonality for example the end of the financial year which is a prerequisite to invest in real estates with the aim of tax facilities, the beginning of the school year for the children, change of jobs, the change of the Stock exchange prices of other basic assets, which are subject to Stock exchange trade, the construction boost in some cities which influences the prices. The presence of a rise in prices in the warm months is proven and a decrease in the cold ones. The average sum in absolute size has been calculated which could be spent by using the seasonal differences in the buying of a flat, which varies from 9700 dollars in Canberra to 21000 dollars in Sydney.

For another big research of the seasonality in the change of the prices of the residential real estates announce (Miller, SAh, Sklarz \& Pampulov, 2012). The authors used the data for the period 2000-2011. It is stated that in the estimation of the estates is ignored the seasonality in the prices, the mistake of $2.78 \%$ could be made. Sources from the USA are quoted, according to which the prices of the 
residential real estates are higher in the summer with $0.86 \%$ to $3.75 \%$. The highest are the prices in June, and the lowest in January. It is suggested the evaluators to make a seasonal correction of the price with a view to reaching a maximum punctuality, because the banks, crediting the purchase of real estate usually press the evaluators to lower the estimations. The same authors: (Miller, Sah, Sklarz \& Pampulov, 2013) in another of their publications announce such results. An analysis of the seasonality on the basis of monthly data for the mean prices in the sales of houses in 138 statistical zones in the USA for the period 2001-2012 by paying attention that this is one of the biggest databases used for such an analysis up to the moment. It has been found out that the average monthly prices deviate from the average annual up to $(-2.78 \%)$ in the winter and up to $(+1.93 \%)$ in the summer. The prices according to the results of the research are the lowest from December to April after which they start increasing. It has been calculated that the average variation of the prices is in the size of $1.16 \%$ and in the summer $1.13 \%$. A specialized software for the definition of the trends of the seasonal components in the development of the received monthly deviations of the prices are a subject to a check for statistical significance, which makes the results extraordinary precise and reliable. It is announced that speculative profits are possible if the buyers take into consideration the seasonal deviations in the prices, but in the mass case when people buy or sell a flat because of the necessity of moving, the waiting of the suitable for a profitable deal season would be accompanied with a number of household and logistical inconveniences. Some original factors have been researched concerning which he authors suppose that could influence the seasonality in the price changes. Usually as factors are pointed out the summer marriages, the beginning of the school year for the children, the change of jobs. But in this case are researched the regional peculiarities of the climate, the development of tourism, the ethnic content of the population. A linear regressive model has been worked out in which a dependable variable is the standard deviation of the seasonal factor, and as factors are included: the relative number of the white Americans in the common number of the population in the populated point, the development of tourism in the populated point, the amplitude in the temperatures in the neighbourhood (the difference between the highest and he lowest). It has been surprisingly found out that the temperature amplitudes are not influenced by seasonality. It has been found out that for the non-tourist cities the seasonality is stronger expressed.

Another such major study has been carried out by (Carliner, 2002). Data for the period 1961 - 2001 for regrouped neighbourhoods in the USA, provided by the Bureau for the calculation of the population were used. It has been found out that the number of sales was highest in June and August (up to 30\% and more) and the lowest in the months from December to February (up to 18\% less). It has been found out that in modern aspect the seasonality in construction has decreased in comparison with the past. The milder winter and the new technologies in construction influence in the direction of decrease of the seasonality in the construction of new homes. Changes in the mean time for the construction of new homes have been found out. It increased from 4.9 month in the beginning of the 1990 to 5.6 months in 2001. As a reason is pointed out the construction of bigger and more complex homes. 
A comparative characteristic of the seasonality in the prices of the flats and the number of sales for UK and USA has been made by (Ngai and Tenreyo, 2014). The data for the prices of the flats and the number of sales for the period $1996-2012$ have been used. For the UK the data for the prices of the flats of the land register, and for the USA by the Agency for federal residential financing, from big banks creditors, and on a regional level from the National association of the brokers have been used. Concerning the neighbourhoods in UK the average difference between the prices of the flats in summer and in winter is $5.5 \%$ whereas the number of deals rises abruptly in the summer months. The revealed degree of seasonality for USA is smaller. It is $4.6 \%$ for the nominal prices and $4.8 \%$ for the real prices. The summer due to the increase in prices and the number of deals is conditionally called "hot season" and the winter "cold season". The presented data for the seasonality point out that June is usually the strongest month for the prices of the flats, and January is the weakest. Concerning the USA the seasonality in the number of deals is huge in summer. In a number of regions it is more than $120 \%$. The influence of some other factors outside the residential market on the seasonality of the prices, and namely the size of the rents and the interest rates on the mortgage credits has been researched. Convincing factors pieces of evidence for the significant influence of these factors have not been revealed. The conclusion is reached that if the flat was bought in summer, the expenditures for repair in the first two years of the buy are $15 \%$ less. A connection of the seasonality in prices and in sales with the continuation of the stay in the flat, the size of the incomes of the inhabitants, the number of people in the household, the inhabited flat, etc. Attempts have been made to model the seasonality in order to be predicted.

In some sources -"Federation of real estate boards" (2017) it is stated that for Canada there is also seasonality in the prices of the flats and the number of sales. The sale prices are usually lower in spring. This is specifically true for Quebeck, where most leasing contracts end on the 30 June. Much more deals are carried out in spring rather than in summer.

Such conclusions are reached by (Kaplanski \& Kaim Levy, 2011) in their research about the USA, UK and Australia. They make the conclusion that in the change of prices of the real estates there is considerable and constant seasonality, in which the highest incomes are received in spring and the beginning of winter. The research comprises the period from 1987 to 2007. The authors state that they have found a new factor, influencing the force of the seasonal effect, and namely the geographical latitude. The bigger it is, the stronger expressed it is according to the seasonality in the prices of the real estates.

\section{USED DATA AND METHODOLOGY}

Monthly data for one-year period since October 2016 to September 2017 for the prices offered for flat sales in one of the biggest sites for flat trade and real estate in Bulgaria - (IMOT.BG) is used. The integrated possibilities of the site for automatic calculations of the mean prices of the basic types of flats due to the fact that sometimes a small mistake in the formulation of the price in some of the announcements or in the try of deliberate manipulation with the help of a fictitious 
announcement are not used, and the mean price gets unrealistic. Such mistake which sometimes could be noticed are for example involuntarily adding one zero in the price, writing the price in leva though the announcement is for euro, etc. Such announcements which are drastically different from the others are deleted. Apart from this in the research are included only these neighbourhoods for which there are more three announcements for the flat in order to lessen the possibility for chance deviations in the calculated common characteristics. Data for three of the most common types of flats on the real estate market in Sofia are used - studios, one-bedroom flats, two-bedroom flats. The real estate market in Sofia is preferred due to its leading role of development in the country. Probably the offer prices are not these for contacting real deals, but if we accept that the price discounts are comparatively equal by neighbourhoods and types of flats, then the offered prices very clearly could reflect the tendency and the seasonality if such really exist. The data used are for a comparatively short period of time which limits the possibility for the application of complex statistical methods for modelling of a tendency, seasonality and cyclicity, but apart from it are maximum concrete for types of flats and neighbourhoods, which makes the info useful only for macroeconomic conclusions and for regional and international comparisons but also for the real consumers from the country and abroad, which are interested in buying a flat. Because for Sofia the level and dynamics of the flat prices by neighbourhoods are considerably different, according to us the calculation of a common mean price would have a limiting knowledge force.

The mean prices by square meter are used, calculated in the participation of all offers for the respective type of flats, because even with the same number of rooms, the prices of the flats vary considerably and we accept that the price by square meter is more clear than the price of whole flats.

Components which could be present in information presented with the help of dynamic lines are: tendency (constant trend), seasonal changes, cyclical changes, cyclical changes, chance fluctuations. For the discovery of a constant trend are necessary to have the enough type of measurements, e.g. the dynamic order to be long enough. There is no commonly accepted rule what this means, but in excerpt research the increase of the number of measurements, e.g., the increase of the size of the excerpt leads to a betterment of the punctuality of the conclusions. The cyclicity is in fact the sustainable change with periodicity more than one year and for its revealing and modeling are necessary annual data from many years. The chance is present in every separate measurement and for its overcoming are necessary data from many years. For the revealing of seasonal fluctuations are necessary monthly or three monthly data for at least one year. In the availability of monthly and three monthly data for several years through the calculations of mean points by months or three months we could talk about the doing away with the chance fluctuations. In the presence of data by months only for one year this possibility does not exist. So, the assumption remains of the availability of a certain dose of unavoidable chance, tendency and seasonality. The tendency could considerably blur the appearance of seasonal fluctuations. That is why tests are made for its finding out and cancelling. On the base of database for the mean levels of prices of separate types of flats (studios, one-bedroom and two-bedroom flats) 
by neighbourhoods in the city of Sofia were carried out tests for the availability of a tendency. For this purpose were calculated the coefficients of auto correlation in lag entity (Kaloyanov \& Petrov 2014, 405).

$$
r_{y_{t} y_{t-1}}=\frac{\sum_{t=2}^{N} y_{t} y_{t-1}-\frac{\sum_{t=1}^{N-1} y_{t} \sum_{t=2}^{N} y_{t}}{N-1}}{\sqrt{\left[\sum_{t=1}^{N-1} y_{t}^{2}-\frac{\left(\sum_{t=1}^{N-1} y_{t}\right)^{2}}{N-1}\right]\left[\sum_{t=2}^{N} y_{t}^{2}-\frac{\left(\sum_{t=2}^{N} y_{t}\right)^{2}}{N-1}\right]}}
$$

An indication of the presence of a trend is the availability of a correlational connection between the neighbouring elements in the dynamic order autocorrelation. The received values were checked for statistical significance through the comparison with table values for the critical meanings of the cyclical coefficients of autorelation in lag 1 from the table of P. Andersen (Velichkova 1981, $72-73,442)$ in the risk of mistake by $5 \%$ which is usual for the economic research. In reality this is a check for the statistical hypothesis. If the calculated values are bigger than the table ones, then the zero hypothesis is thrown away and with a definite probability could be stated that we have a trend. After the presence of trend is confirmed, there is a possibility it to be defined as a form, modeled with the help of statistical functions and after that could be calculated extra-pollar prognosis with short term horizon up to several months. It constantly changes and the tendency is in a way blurred by the chance circumstances connected with the characteristics of the flats and the subjective appraisal of the owners concerning the offered price.

For the neighbourhoods for which the calculated value about the autocorrelation coefficient is smaller or equal to the table one, there is no reason to throw away the zero hypothesis and it is accepted. In the absence of a trend, the dynamic levels were researched for seasonality by the method of the simple mean chronological (Stoenchev 2013, p. 271).

1. It is calculated the mean chronological for the whole researched period. This is the mean monthly value, which presents the point in such kind which it could have if there were no seasonal fluctuations. In the work with monthly data, the sum of the values of the point annually is divided into 12 :

$$
\bar{y}=\frac{y_{I}+y_{I I}+y_{I I I}+\ldots+y_{X I I}}{12}
$$

2. Indices are calculated of the seasonal deviations as a relation of the monthly values to the mean chronological:

$$
I_{S_{i}}=\frac{y_{i}}{\bar{y}} \cdot 100
$$


In values of the index above 100, there are positive deviations of the monthly values from the mean for the year by seasonal reasons, and in values under 100 there are negative deviations of the monthly values.

\section{FINDINGS OF THE STUDY}

On the basis of the data for the offered prices for studios in Sofia, the highest statistical considerable values for the coefficient of auto-correlation from the first order were received for the neighbourhoods: Mladost 1A, Manastirski livadi, Nadezhda 1, Druzhba2, Ovcha Kupel 1, Hadji Dimitar. For these neighbourhoods it is logical to accept that the tendency is most clearly defined. In order to adopt a visual image concerning the dynamics of the price offers in these neighbourhoods in the viewed period are presented graphically in Figure 1.

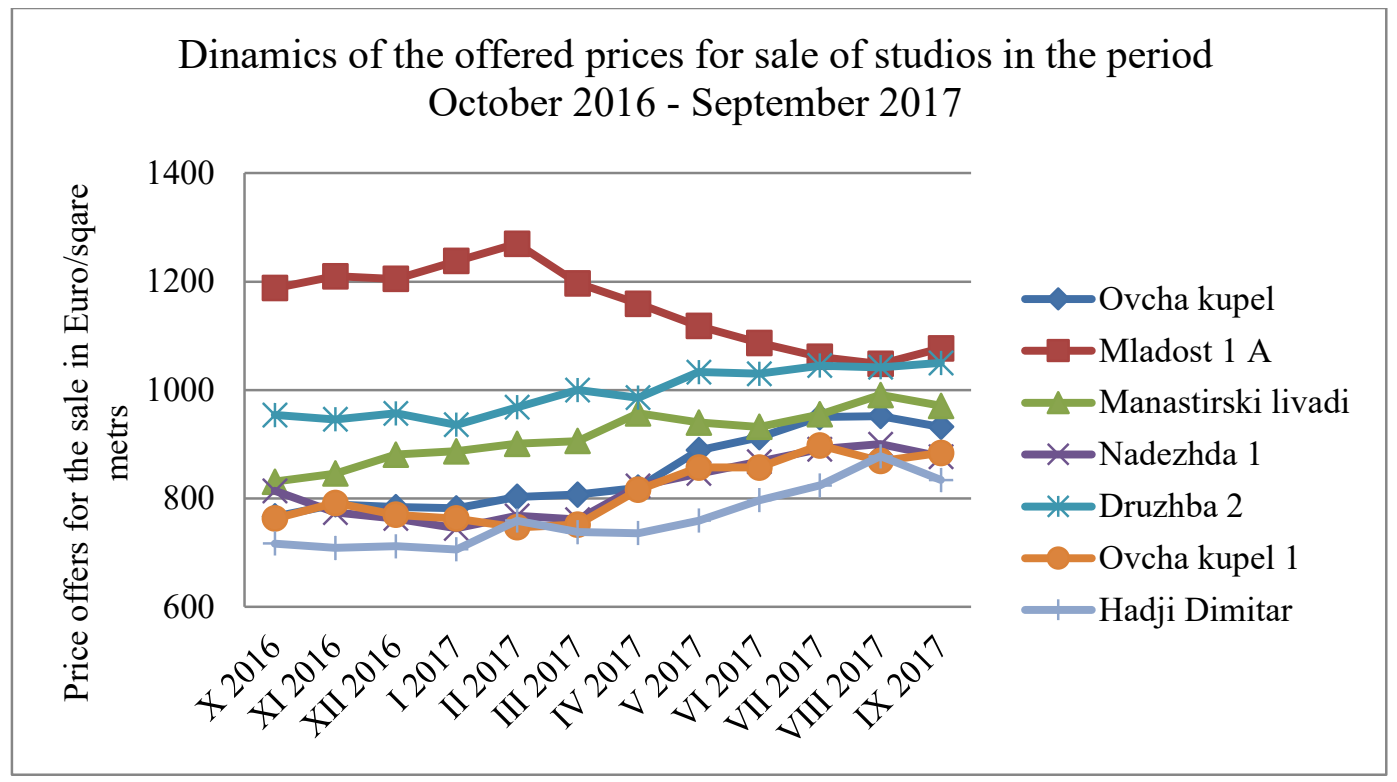

Fig. 1. Dynamics of the offered prices for the sale of studios in some neighbourhoods in Sofia in the period October 2016 - September 2017 (developed by the authors, using www.imot.bg)

Among the presented seven neighbourhoods in six there is an upper tendency, and in one-Mladost 1A there is a downward tendency. In the end of the period the prices are clearly focused in more limited borders than those at the end of the period.

The analysis of the availability of a constant trend in the change of the offered prices for studios shows that in most cases it is available, but there are neighbourhoods for which it is not such and the prices fluctuate around the middle. For the researched period such are the neighbourhoods: Dianabad, Iztok, Krustova Vada, Levski, Lozenets, Lulin 3, 5, 6, Mladost 2, Suhata reka, Centre. About the enumerated neighbourhoods the calculated coefficients of auto correlation appeared statistically irrelevant, e.g. smaller than the absolute values from the tables. 
The lack of a tendency in the price changes in these neighbourhoods gives the possibility to carry out an analysis for the availability of seasonality. In Table 1 are presented the seasonality indices for the neighbourhoods group for which it was not considered availability of a price change.

Table 1. Indices for seasonality in the change of the preferred prices for sale of studios for some neighbourhoods in Sofia in \% (compiled by the authors, using www.imot.bg)

\begin{tabular}{|c|c|c|c|c|c|c|c|c|c|c|c|c|}
\hline $\begin{array}{l}\text { Neighbour } \\
\text { hood }\end{array}$ & $\begin{array}{c}X \\
' 16\end{array}$ & $\begin{array}{l}\text { XI } \\
\text { '16 }\end{array}$ & $\begin{array}{l}\text { XII } \\
\text { '16 }\end{array}$ & $\begin{array}{c}\text { I } \\
' 17\end{array}$ & $\begin{array}{l}\text { II } \\
\text { 117 }\end{array}$ & $\begin{array}{l}\text { III } \\
\text { 117 }\end{array}$ & $\begin{array}{l}\text { IV } \\
\text { '17 }\end{array}$ & $\begin{array}{c}\text { V } \\
' 17\end{array}$ & $\begin{array}{l}\text { VI } \\
\text { '17 }\end{array}$ & $\begin{array}{l}\text { VII } \\
\text { '17 }\end{array}$ & $\begin{array}{l}\text { VIII } \\
\text { '17 }\end{array}$ & $\begin{array}{l}\text { IX } \\
\cdot 17\end{array}$ \\
\hline Dianabad & 97.2 & 97.6 & 97.6 & 99.0 & 103.3 & 100.8 & 102.9 & 103.1 & 98.4 & 98.3 & 102.2 & 99.6 \\
\hline Iztok & 68.7 & 103.6 & 105.0 & 115.2 & 108.6 & 107.4 & 103.8 & 94.6 & 86.2 & 97.4 & 98.0 & 111.5 \\
\hline $\begin{array}{l}\text { Krusto } \\
\text { vada }\end{array}$ & 96.6 & 96.9 & 96.8 & 98.2 & 100.9 & 96.9 & 103.0 & 100.9 & 102.8 & 98.3 & 94.0 & 114.7 \\
\hline Levski & 86.8 & 93.2 & 93.2 & 98.1 & 97.9 & 97.9 & 99.0 & 99.0 & 104.3 & 104.6 & 97.7 & 128.2 \\
\hline Lozenets & 99.3 & 96.1 & 95.7 & 99.7 & 103.3 & 103.8 & 108.8 & 105.8 & 104.5 & 90.1 & 103.3 & 89.5 \\
\hline Lulin 3 & 91.8 & 88.4 & 98.3 & 91.6 & 86.0 & 114.4 & 100.5 & 102.0 & 106.9 & 105.1 & 107.8 & 107.3 \\
\hline Lulin 5 & 98.7 & 98.8 & 99.7 & 95.5 & 103.4 & 101.9 & 96.3 & 99.2 & 102.0 & 100.5 & 98.8 & 105.0 \\
\hline Lulin 6 & 98.1 & 103.0 & 105.5 & 100.0 & 97.5 & 94.1 & 101.2 & 101.7 & 97.6 & 99.8 & 99.8 & 101.6 \\
\hline Mladost 2 & 97.1 & 98.1 & 99.6 & 99.1 & 107.3 & 98.4 & 102.7 & 96.1 & 97.1 & 97.3 & 103.5 & 103.8 \\
\hline Suhata reka & 96.3 & 93.1 & 100.7 & 103.5 & 100.8 & 101.0 & 101.7 & 97.0 & 96.1 & 103.4 & 99.9 & 106.6 \\
\hline Center & 89.6 & 103.8 & 106.2 & 102.6 & 97.1 & 99.1 & 66.0 & 98.1 & 100.4 & 108.5 & 114.9 & 113.5 \\
\hline $\begin{array}{l}\text { Mean value of } \\
\text { the index }\end{array}$ & 92.8 & 97.5 & 99.9 & 100.2 & 100.6 & 101.4 & 98.7 & 99.8 & 99.7 & 100.3 & 101.8 & 107.4 \\
\hline
\end{tabular}

The received results about the researched group of neighbourhoods definitely shows the presence of a moderate to weak seasonality in the price changes, which in the high prices of the flats is not without significance for the investors. The highest are the middle prices of the studios in August and September and the lowest in October and November. What is common for the group of neighbourhoods in which a tendency was not discovered for the deviation of the mean monthly prices of the one flat residences from the mean annual price varies from $-7.2 \%$ in October 2016 to +7.4 in September 2017. 
Such an analysis was carried out separately and for the change in the prices in the one-bedroom and two-bedroom flats residences in the same period. The following results were received:

In the one-bedroom flats the highest values concerning the coefficient of autocorrelation which are statistically significant were received about the neighborhoods: Centre, Mladost 2, Dianabad, Lulin 7, Studentski grad, Poligona, Reduta, Bukston, Mladost 1, Druzhba 2. The values vary from 0.988 to 0.931 . This is an indication for the availability of a sustainable tendency. The first seven neighbourhoods with received highest values for the coefficient of auto-correlation are presented in Figure 2.

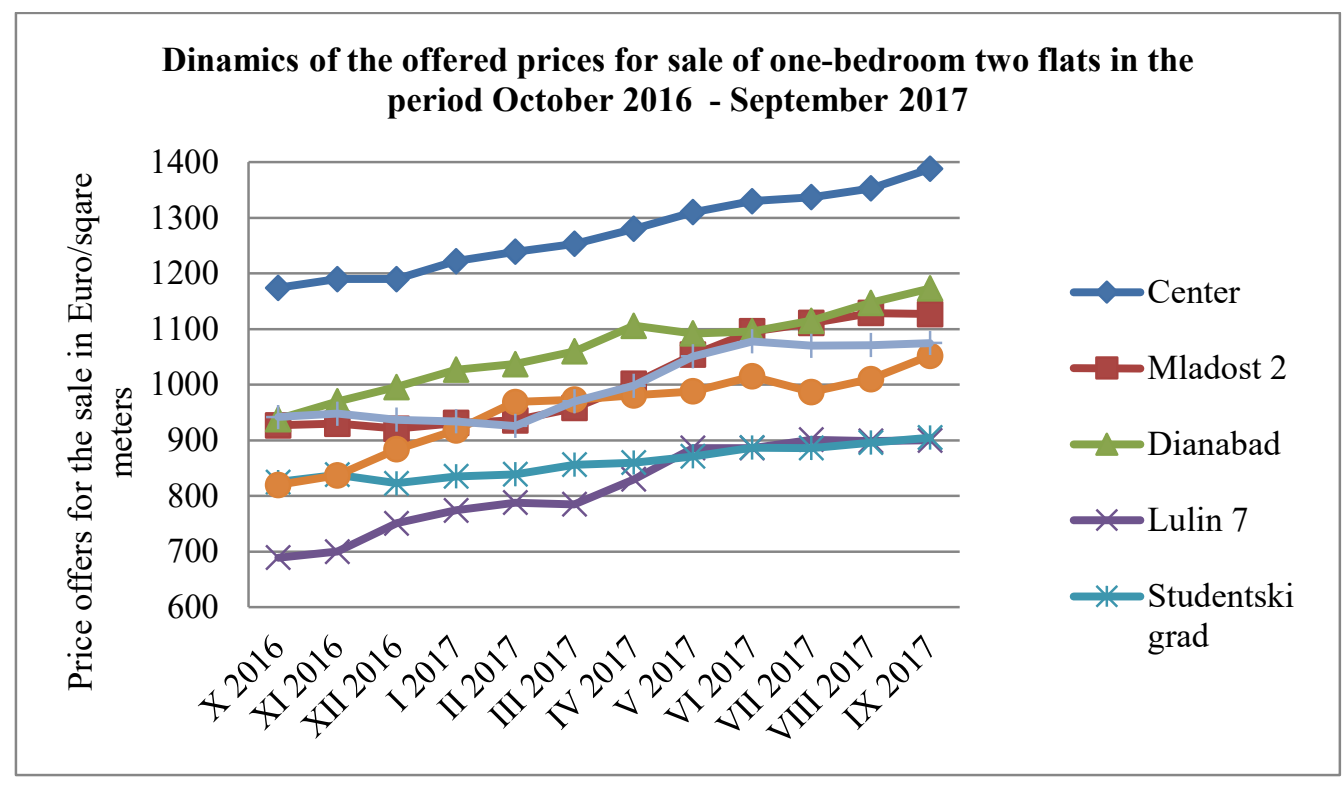

Fig. 2. Change of the offered prices for the sale of one-bedroom flats in the period October 2016 to September 2017 for some neighbourhoods of Sofia (developed by the authors, using www.imot.bg)

From the figure it is noticed that in all neighbourhoods there is a sustainable rise of the offered prices whereas the price differences between the presented neighbourhoods in the beginning and the end of the period is kept in broad borders. The slant of the lines is different. For Studentski grad the increase is very smooth and not that considerable as in the other neighbourhoods.

The hypothesis for the lack of a tendency was thrown away for all researched neighbourhoods with the exception of the neighbourhoods: Mladost 4, Lulin 3, Yavorov, Obela 2, Medical Academy, Lozenets, Izgrev. About them with the probability of $95 \%$ the zero hypothesis could be accepted, e.g. with a quoted punctuality it could be stated that the data do not give ground to accept the presence of a constant trend in the change.

Concerning these neighbourhoods was carried out an analysis of the availability of seasonality. The results from the analysis are presented in Table 2. 
Table 2. The indices of seasonality in the change of the offered prices for sale of one-bedroom flats for a group of neighbourhoods in Sofia in \% (developed by the authors, using www.imot.bg)

\begin{tabular}{|c|c|c|c|c|c|c|c|c|c|c|c|c|}
\hline $\begin{array}{l}\text { Neighbour } \\
\text { hood }\end{array}$ & $\underset{1}{X}$ & $\begin{array}{l}\text { XI } \\
' 16\end{array}$ & $\begin{array}{l}\text { XII } \\
' 16\end{array}$ & $\underset{17}{I}$ & $\underset{1}{\text { II }}$ & $\begin{array}{l}\text { III } \\
' 17\end{array}$ & $\begin{array}{l}\text { IV } \\
' 17\end{array}$ & $\begin{array}{l}\text { V } \\
17\end{array}$ & $\begin{array}{l}\text { VI } \\
' 17\end{array}$ & $\begin{array}{l}\text { VII } \\
' 17\end{array}$ & $\begin{array}{l}\text { VIII } \\
' 17\end{array}$ & $\begin{array}{l}\text { IX } \\
' 17\end{array}$ \\
\hline Mladost 4 & 90.4 & 94 & 95.3 & 94.1 & 97.6 & 103 & 107.4 & 107.6 & 110.6 & 109.5 & 111.3 & 79.3 \\
\hline Lulin 3 & 98.7 & 98.1 & 100.4 & 96.4 & 92.3 & 96.4 & 108.7 & 104.9 & 97 & 95.1 & 105.8 & 106.3 \\
\hline Iavorov & 97 & 103 & 96.2 & 99.8 & 99.6 & 98 & 93.2 & 100.1 & 99.5 & 106 & 102.4 & 105.7 \\
\hline Obela 2 & 98.6 & 97.6 & 101.2 & 98.9 & 102.2 & 102.5 & 100.6 & 101.2 & 101.3 & 98.3 & 99.9 & 97.9 \\
\hline $\begin{array}{l}\text { Medical } \\
\text { academy }\end{array}$ & 105 & 99.2 & 95.5 & 100 & 101.6 & 97.9 & 100.2 & 96.7 & 100.9 & 103.5 & 101.6 & 98 \\
\hline Lozenets & 97.4 & 96 & 98.2 & 98.8 & 100.9 & 103.7 & 103.7 & 106.5 & 105.9 & 72.9 & 107.3 & 108.8 \\
\hline Izgrev & 115 & 85.8 & 96.8 & 97.2 & 98.5 & 110.5 & 95.5 & 96.6 & 92.5 & 99.5 & 107.2 & 104.6 \\
\hline $\begin{array}{l}\text { Mean value } \\
\text { of the index }\end{array}$ & 100 & 96.2 & 97.7 & 97.9 & 98.9 & 101.7 & 101.3 & 101.9 & 101.1 & 97.8 & 105.1 & 100.1 \\
\hline
\end{tabular}

It appeared that the moderate seasonality in the change of prices exists and it is in the direction towards lessening in the late autumn and winter and increase in spring and summer. There is a clearly expressed increase in prices in August. The closest to the mean for the year are the prices in September and October. The highest deviations of the mean monthly prices from the middle prices of the year for the group of neighbourhoods was discovered for November $2016(3.8 \%)$ and for August 2017 ( $+5.1 \%)$.

In order to discover the degree of sustainability in the change of price in the two-bedroom flats was carried a test for the presence of a tendency with the help of a coefficient of auto-correlation from first order.

On Fig. 3 is presented the change of prices for neighbourhoods in which the highest values in the coefficient of auto-correlation are presented. 


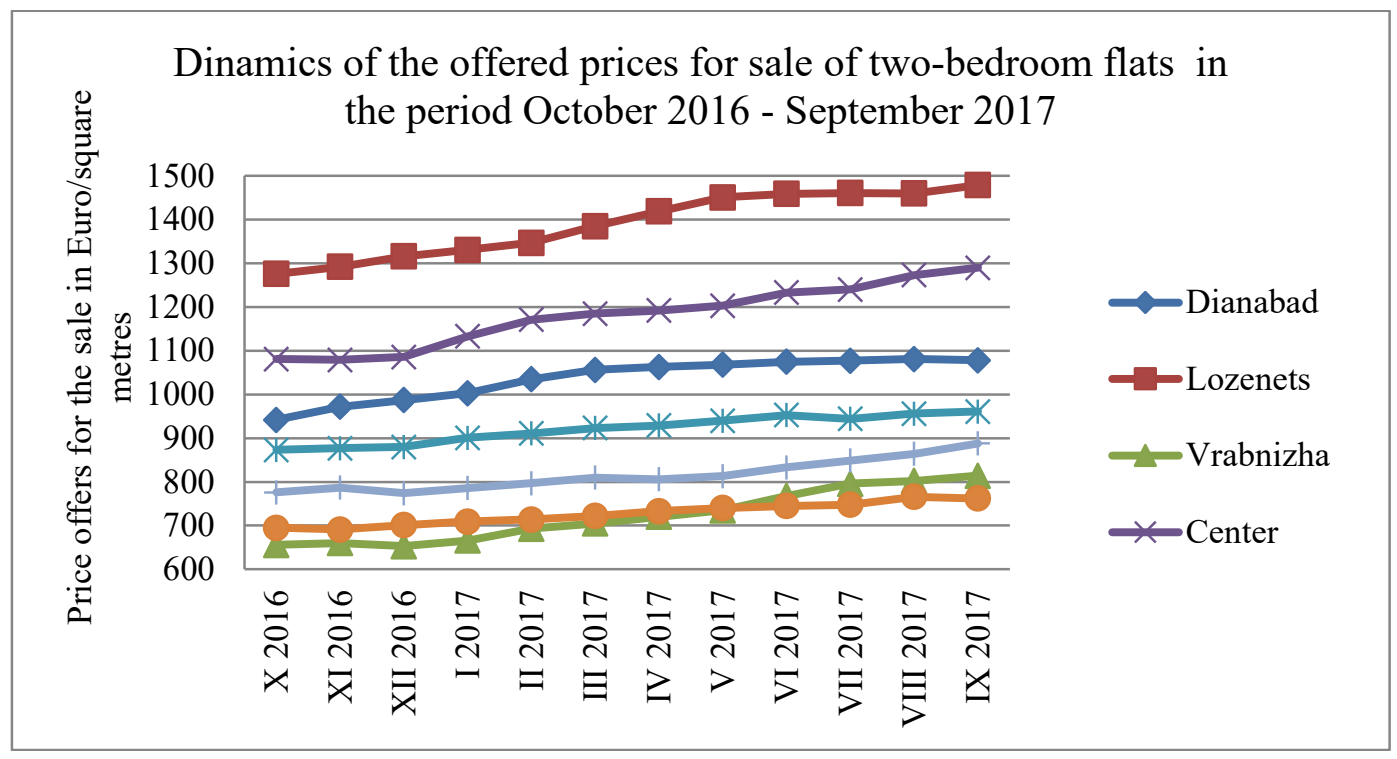

Fig. 3. Dynamics of the offered prices for sale of two-bedroom flats in the period from October 2016 to September 2017 for some neighbourhoods in Sofia (developed by the authors, using www.imot.bg)

In all presented neighbourhoods is noticed a fluent and irreversible increase in prices because of which the fluctuation in the prices between the represented neighbourhoods in the beginning and the end of the research period remains comparatively the same and significant.

The presence of a tendency was not proven only for four of the neighbourhoods which make them suitable for research of the seasonality by the method of the simple mean chronological. The values of the index of seasonality of the research period are presented in Table 3.

Table 3. Indices for seasonality in the change of the offered prices for sale of twobedroom flats in some neighbourhoods of Sofia for the period October 2016 -

September 2017.

\begin{tabular}{|c|c|c|c|c|c|c|c|c|c|c|c|c|}
\hline $\begin{array}{l}\text { Neighbour } \\
\text { hood }\end{array}$ & $\begin{array}{c}X \\
16 \\
\end{array}$ & $\begin{array}{l}\mathrm{XI} \\
' 16 \\
\end{array}$ & $\begin{array}{l}\text { XII } \\
' 16 \\
\end{array}$ & $\begin{array}{c}I \\
17 \\
\end{array}$ & $\begin{array}{l}\text { II } \\
' 17 \\
\end{array}$ & $\begin{array}{l}\text { III } \\
\text { '17 } \\
\end{array}$ & $\begin{array}{l}\text { IV } \\
\text { '17 } \\
\end{array}$ & $\begin{array}{c}\mathrm{V} \\
\cdot 17 \\
\end{array}$ & $\begin{array}{l}\text { VI } \\
\text { '17 } \\
\end{array}$ & $\begin{array}{l}\text { VII } \\
\text { '17 } \\
\end{array}$ & $\begin{array}{l}\text { VIII } \\
\text { '17 } \\
\end{array}$ & $\begin{array}{l}\text { IX } \\
1 \mathbf{1 7} \\
\end{array}$ \\
\hline Zona B-19 & 98.3 & 98.9 & 100.2 & 102 & 98.8 & 99 & 100 & 101 & 99.4 & 98.4 & 102.3 & 102.2 \\
\hline Crasna & \multirow{2}{*}{97.9} & \multirow{2}{*}{93.4} & \multirow{2}{*}{92.5} & \multirow{2}{*}{94.3} & \multirow{2}{*}{96.1} & \multirow{2}{*}{97.3} & \multirow{2}{*}{98} & \multirow{2}{*}{98.2} & \multirow{2}{*}{106} & \multirow{2}{*}{105} & \multirow{2}{*}{110.3} & \multirow{2}{*}{111.2} \\
\hline poliana 1 & & & & & & & & & & & & \\
\hline Nadezhda 3 & 92.4 & 98.2 & 100.2 & 99.4 & 101.5 & 101 & 102 & 98.5 & 98.8 & 98.3 & 108 & 102.4 \\
\hline Poduiane & 97.7 & 101 & 101 & 95.3 & 97.3 & 106 & 101 & 98.2 & 99.4 & 97.6 & 101.5 & 104.7 \\
\hline $\begin{array}{l}\text { Mean value of } \\
\text { the index }\end{array}$ & 95.4 & 96.5 & 96.9 & 96.6 & 97.9 & 100 & 100 & 99.6 & 102 & 102 & 106.6 & 106.6 \\
\hline
\end{tabular}


The lowest appear to be the offered prices for sale in the late autumn and winter, in the spring are close to the mean for the year, and in the summer and early autumn - the months June, July, August and September - the prices point out to their highest values. The most considerable are the deviations of the mean monthly prices for the year in the two-bedroom flats in the group of neighbourhoods in the month of October $2016(-4.6 \%)$ and for the months of August and September $2017(+6.6 \%)$.

\section{CONCLUSION}

The research of the seasonal component in the change of the prices shows a moderate increase of the mean offered prices in the summer months and the early autumn and decrease in the late autumn and winter. It makes an impression the steep fall of the prices from the months August and September, which are in its highest from October to November, when they are at its lowest. The most significant is the change in the variation of prices in the studios, followed by the two-bedroom flats and the one-bedrooms flats. If in these results is contained a certain chance it could be defined by observations of many years. As a whole they answer the characteristics of the market of real estates in Sofia, on which separate consumers dominate, aiming to satisfy their flat necessities or to put part of their savings in them. That is why the end of the summer, when the summer holidays end and the students start school appears to be a peak moment in the looking for flats which from its side effects the prices. The fact that in Bulgaria still the main part of the new flats are offered for sale only in its basic first construction without furnishing which requires additional work so that the flats are put into exploitation and at the moment for a comfortable moving and easier lease it ends comparatively in this season.

The revealed seasonality in the change of prices could very difficultly be used for not very fair profits due to the presence of not a few household expenses on the servicing of the deals by buying and selling. We have in mind the commissions of the brokers which are usually 3-4\% from the value of the deal, the charge at the Agency for flat listings, the notary fees and other expenses.

It deserves attention the revealed tendency to rise in prices in the bigger part of the neighbourhoods in Sofia and the three types of flats which gives the reason to accept that the investment in the buying of a flat after a certain period of time could bring profit even if it is not rented.

\section{REFERENCES}

Boards Quebec Federation of real estate. (2017). Seasonality and the Interpretation of Real Estate. Retrieved from http://www.fciq.ca/real-estate-market/real-estate-marketstatistics/aboutstatistics/seasonality-and-interpretation-of-real-estate-statistics/.

Carliner, M. (2002). "Seasonality in the housing market". Retrieved from http://www.michaelcarliner.com/HE0211-Seasonality.pdf

IMOT.BG. Retrieved from www.imot.bg

Kaplanski, G., \& Levy, K. (2011). Real estate prices: An international study of seasonality's sentiment effect. Journal Of Empirical Finance 19(1), 123-146. 
Miller, N., Sah, V., Sklarz, M., \& Pampulov, S. (2012). Norm Correcting For The Effects Of Seasonality On Home Prices. The Appraisal Journal, 46-53.

Miller, N., Sah, V., Sklarz, M., \& Pampulov, S. (2013). Is There Seasonality In Home PricesEvidence From CBSAs. Journal Of Housing Research, 22(1).

Ngai, L., \& Tenreyro, S. (2014). Hot and Cold Seasons in the Housing Market. American Economic Review, 104(12), 3991-4026. https://doi.org/10.1257/aer.104.12.3991

Valadkhani, A., Worthington, A., \& Smith, R. (2015). Seasonality in Australian, Capital City House and Unit Prices. Australia: Griffith Business School.

Velichkova, N. (1981). Statistical Methods for studying and forecasting the development of the social-economic events. Sofia: Science and Art.

Kaloyanov, T. \& Petrov, V. (2014). Statistics. Sofia: Publishing complex of the University for National and World Economy.

Stoenchev, N. (2013). Statistics. Sofia: Publishing House of the University of Forestry.

\section{AUTHORS' SHORT BIOGRAPHIES}

Nikolay Stoenchev, is a Professor PhD of the Faculty of "Business Management" and Head of the Department "Economics" at University of Forestry, Sofia, Bulgaria. His teaching and scientific works include Statistics, Management information systems, Regional Economics, Public Administration, Real Estate and etc. The author is member of the Faculty Scientific Council, member of the editorial board of the journal "Real estate property \& Business" issued from the academic staff of "Real Estate Property" Department of Business Faculty of University of National and World Economy - Sofia, Bulgaria and member of the editorial board of the journal "Management and sustainable development" in Faculty of Business Management, University of Forestry, Sofia. Nikolay Stoenchev is the author and co-author of more than 80 scientific publications.

Contact: 1756 Sofia, bul. Kliment Ohridski 10, Sofia, Bulgaria.

E-mail:mai3@abv.bg

Yana Hrischeva is a chief assist. dr. of the Faculty of "Business" in the department "Real Estate Property" at University of national and world economy, Sofia, Bulgaria. She received a PhD degree in economics from UNWE in 2016. The topic of her dissertation was "Marketing aspects for increase of investment return on residential properties within the city of Sofia. She has a bachelor degree in psychology of economics and two Masters degrees at the same university. Her first master is Marketing and her second master is public finances. Her research and teaching interests include real estate marketing, market analysis and forecast, investments in real estate property, human resource and etc.

Contact: 1700 Sofia, Studentski grad "Hr. Botev" Sofia, Bulgaria.

E-mail:hrischeva.y@abv.bg 